Case Reports in
Gastroenterology
Case Rep Gastroenterol 2020;14:604-608

DOI: 10.1159/000509737

Published online: November 4, 2020

(C) 2020 The Author(s)

Published by S. Karger AG, Basel www.karger.com/crg

This article is licensed under the Creative Commons Attribution-NonCommercial 4.0 International License (CC BY-NC) (http://www.karger.com/Services/OpenAccessLicense). Usage and distribution for commercial purposes requires written permission.

\title{
An Unexpected Complication of Endoscopic Retrograde Cholangiopancreatography with a Novel Treatment Approach
}

\author{
Jeremy Polman Aaron C. Williams Gaetano Ruggiero Aaron DeWitt
}

Internal Medicine Residency Program, Baton Rouge General, Baton Rouge, LA, USA

\section{Keywords}

Choledocholithiasis · Endoscopic retrograde cholangiopancreatography · Gastroenterology · Splenic artery embolization $\cdot$ Splenic injury

\section{Abstract}

Splenic injury after endoscopic retrograde cholangiopancreatography (ERCP) has been documented in less than 30 cases. Here, we present a case that involves a 52 -year-old male with choledocholithiasis who developed a splenic injury and major hemorrhage immediately after ERCP. The patient ultimately required splenic artery embolization without splenectomy, a novel treatment approach. The case demonstrates the importance of having a high index of suspicion of this rare complication as well as discusses potential causes of post-ERCP splenic injury and a treatment approach that does not involve splenectomy.

(C) 2020 The Author(s)

Published by S. Karger AG, Basel

\section{Introduction}

Endoscopic retrograde cholangiopancreatography (ERCP) is an invasive technique in which an endoscope is passed from the mouth, down the esophagus, through the stomach, and to the hepato-pancreatic ampulla. This is a technique that can diagnose and perform interventional procedures related to biliary tract and pancreatic pathology. Complications from an 


\section{Case Reports in Gastroenterology}

Case Rep Gastroenterol 2020;14:604-608 DOI: $10.1159 / 000509737$

(c) 2020 The Author(s). Published by S. Karger AG, Basel www.karger.com/crg

Polman et al.: An Unexpected Complication of ERCP with a Novel Treatment Approach

ERCP range from about 6 to $10 \%$ and carry an overall mortality of $0.5-1 \%[1,2]$. The most common complications after an ERCP include acute pancreatitis, esophageal/duodenal perforation, and infection [3]. One rare and life-threatening complication, having less than 30 documented cases, is splenic injury. Here, we describe the case of a 52-year-old male who had one such complication.

\section{Case Report/Case Presentation}

A 52-year-old male with no past medical history presents to the emergency department with a chief complaint of abdominal pain and a fever at home of $101^{\circ} \mathrm{F}$. He states that the abdominal pain was intermittent for the last week, but has now become a constant, sharp, and stabbing sensation in the right upper quadrant of his abdomen. Physical exam findings included severe tenderness to palpation in the right upper quadrant of the abdomen as well as voluntary guarding and a positive Murphy sign. Laboratory values included a total bilirubin of $3 \mathrm{mg} / \mathrm{dL}$, direct bilirubin of $2.3 \mathrm{mg} / \mathrm{dL}$, AST of $309 \mathrm{U} / \mathrm{L}$, ALT of $319 \mathrm{U} / \mathrm{L}$, and an alkaline phosphatase of $173 \mathrm{U} / \mathrm{L}$. CT imaging in the emergency department revealed a distended gallbladder with multiple gallstones and pericholecystic fluid in the setting of biliary ductal obstruction, causing a 11-mm common bile duct dilation. Follow-up MCRP revealed intrahepatic and extrahepatic bile duct dilation with distal common bile duct filling defects, compatible with choledocholithiasis. The patient was then given an NPO status to prepare for ERCP followed by laparoscopic cholecystectomy the following day.

ERCP with common bile duct stenting was performed the following day. The procedure was complicated by a difficult to cannulate hepato-pancreatic ampulla, requiring a prolonged procedure time. After completion of the ERCP, the patient was then repositioned to prep and drape the abdomen for laparoscopic surgery. Upon entry, significant hemoperitoneum of uncertain etiology was encountered. Examination of the gallbladder, newly placed common bile duct stent, and newly dilated hepato-pancreatic ampulla did not reveal brisk bleeding. Attention was then turned to the spleen, which demonstrated a large amount of blood pooling as well as disruption of the anterior and superior splenic poles. Active hemorrhaging was controlled with electro-cautery, pressure, and multiple sheets of absorbable hemostat. Once the hemorrhaging was controlled, the large, tense, and enflamed gallbladder was removed, which included 3 golf ball-sized stones. As the procedure concluded, patient received one unit of packed red blood cells secondary to an estimated intraoperative blood loss of 1,200 mL. The patient was then brought to the intensive care unit for monitoring as well as serial hemoglobin.

Shortly after arriving to the intensive care unit, the patient became hypotensive with a repeat hemoglobin at $5.7 \mathrm{~g} / \mathrm{dL}$. The patient was resuscitated with two units of packed red blood cells as well as $1 \mathrm{~L}$ of lactated ringers and stabilized. Overnight, however, the patient once again became hypotensive as well as developed increased bloody output from closed suction postoperative drains, requiring him to receive 5 units of packed red blood cells, 1 unit of fresh frozen plasma, and 1 unit of platelets. The patient was then taken emergently to interventional radiology for splenic artery embolization. Embolization was successfully completed using endovascular coiling with no complications. Post-procedural CT abdomen and pelvis can be seen in Figures 1, 2. After embolization, the rest of the patient's hospital stay was uneventful. Upon resolution of his symptoms and stabilization of hemoglobin, the patient was discharged home. 


\section{Case Reports in Gastroenterology}

\begin{tabular}{l|l}
\hline Case Rep Gastroenterol 2020;14:604-608 \\
\hline DOI: 10.1159/000509737 & $\begin{array}{l}\text { @ 2020 The Author(s). Published by S. Karger AG, Basel } \\
\text { www.karger.com/crg }\end{array}$ \\
\hline
\end{tabular}

Polman et al.: An Unexpected Complication of ERCP with a Novel Treatment Approach

\section{Discussion/Conclusion}

As demonstrated in the case, post-ERCP splenic injury can quickly become a fatal complication if not treated promptly. It is vital that the physician team remain aware and have a high index of suspicion of this complication so that they may intervene appropriately, as delayed diagnosis can lead to a fatal outcome. Signs and symptoms that a clinician team can look for are left upper quadrant abdominal pain, epigastric pain, and hemodynamic instability. However, these signs and symptoms are not specific and overlap with common complications of ERCP, including pancreatitis, post-sphincterotomy bleeding, and esophageal/duodenal perforation [4]. Symptoms may present promptly after the procedure or may insidiously appear over a few days. The diagnosis can be confirmed emergently using a bedside ultrasound to assess for hemorrhage, urgently using a CT scan, or (as in the case presented) intraoperatively through direct visualization. Of the less than 30 documented cases, successful treatment required splenectomy in about $80 \%$ of cases [5]. With the advancement in medical management and interventional radiological procedures, this case demonstrates a new way to treat postERCP splenic lacerations without the need for splenectomy, shown in Figure 1 and 2.

The specific mechanism of post-ERCP splenic injury remains unknown. One potential explanation that fits with the case presented involves the bowing and torsion of the endoscope while attempting to cannulate a difficult hepato-pancreatic ampulla. During this procedure, torsion on the greater curvature of the stomach will translate to direct forces on the surrounding organs, including the splenic capsule and vasculature [6]. Another potential explanation is that of anatomical changes secondary to chronic pancreatitis. Chronic pancreatitis may lead to fibrosis and calcification of the splenocolic and gastrosplenic ligaments [7]. Ligamentous fibrosis and calcification may then lead to rupture with moderate traction during an ERCP. One final potential explanation is anatomical changes secondary to previous abdominal surgery. Similar to chronic pancreatitis leading to fibrosis of abdominal ligaments, it is possible that adhesions from previous surgeries may result in fragility of splenic ligaments, leading to rupture post-ERCP [5].

In conclusion, splenic injury is a rare, but potentially fatal complication to ERCP. As demonstrated in the case, a high index of suspicion is vital to properly manage such a complication. With the always improving capabilities of interventional radiological procedures, splenic artery embolization can potentially prevent splenectomy as a result of post-ERCP splenic laceration.

\section{Statement of Ethics}

The subject of the above case report has provided their written informed consent to publication of the case and images.

\section{Conflict of Interest Statement}

The authors have no conflicts of interest to declare. 


\section{Case Reports in Gastroenterology}

\section{Funding Sources}

No funding source was required for this case report.

\section{Author Contributions}

Jeremy Polman, DO: Dr. Polman in the primary author of this manuscript. He had direct interaction with the patient's medical records and interpreted all information relevant to the case. He personally collected all information required for the manuscript completion. Jeremy Polman has approved the final version of the manuscript.

Aaron Williams, MD: Dr. Williams was directly involved in the patient's care. He gathered information necessary for creation of the manuscript. He helped research specific information from various medical journals during research and reference creation. Aaron Williams has approved the final version of the manuscript.

Gaetano Ruggiero, MD: Dr. Ruggiero was directly involved in the patient's care. He gathered information necessary for creation of the manuscript. He helped research specific information from various medical journals during research and reference creation. Gaetano Ruggiero has approved the final version of the manuscript.

Aaron DeWitt, MD: Dr. DeWitt is the academic chair of scholarly activities at the Baton Rouge General Internal Medicine residency program. He assisted in the editing of the manuscript, directed research toward specific articles, and helped organize the manuscript in a logical manner. Aaron DeWitt has approved the final version of the manuscript.

\section{References}

1 Pannu HK, Fishman EK. Complications of endoscopic retrograde cholangiopancreatography: spectrum of abnormalities demonstrated with CT. Radiographics. 2001 Nov-Dec;21(6):1441-53.

2 Aliperti G. Complications related to diagnostic and therapeutic endoscopic retrograde cholangiopancreatography. Gastrointest Endosc Clin N Am. 1996 Apr;6(2):379-407.

3 Cotton PB, Garrow DA, Gallagher J, Romagnuolo J. Risk factors for complications after ERCP: a multivariate analysis of 11,497 procedures over 12 years. Gastrointest Endosc. 2009 Jul;70(1):80-8.

4 Al Momani L, Karar S, Shipley LC, Locke A, Swenson J. Endoscopic Retrograde CholangiopancreatographyInduced Splenic Injury in a Patient With Sleeve Gastrectomy. J Investig Med High Impact Case Rep. 2018 Jun;6:2324709618779417.

5 Lee R, Huelsen A, Saad N, Hodgkinson P, Hourigan LF. Splenic Injury Following Endoscopic Retrograde Cholangiopancreatography: A Case Report and Literature Review. Case Rep Gastroenterol. 2017 Apr;11(1):241-9.

6 Pamudurthy V, Abraham RZ, Betlej T, Shah A, Kim D, Sasso B, et al. Etiologies and risks of splenic decapsulation after endoscopic retrograde cholangiopancreatography: case report and literature review. Endosc Int Open. 2018 Mar;6(3):E271-3.

7 Gaffney RR, Jain V, Moyer MT. Splenic Injury and ERCP: A Possible Risk for Patients with Advanced Chronic Pancreatitis. Case Rep Gastroenterol. 2012 Jan;6(1):162-5. 
Case Reports in Gastroenterology
Case Rep Gastroenterol 2020;14:604-608

DOI: $10.1159 / 000509737$

(c) 2020 The Author(s). Published by S. Karger AG, Basel www.karger.com/crg

Polman et al.: An Unexpected Complication of ERCP with a Novel Treatment Approach

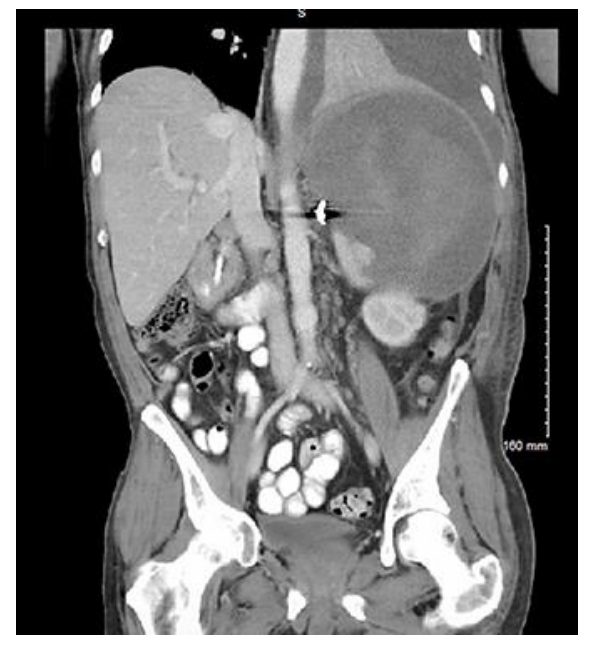

Fig. 1. Coronal slice of CT abdomen and pelvis demonstrating large splenic hematoma post-ERCP with splenic artery embolization.

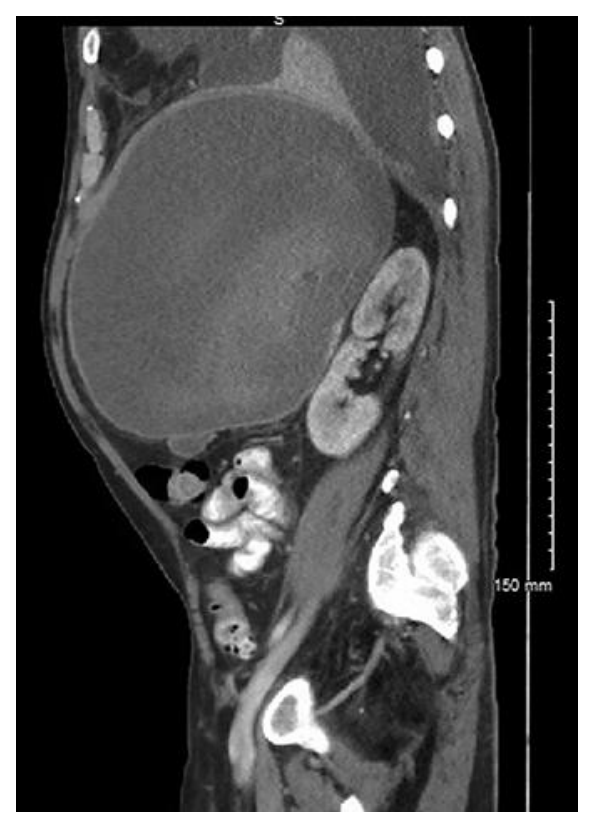

Fig. 2. Anterior-posterior slice of CT abdomen and pelvis demonstrating large splenic hematoma postERSP with splenic artery embolization. 